\title{
The Effect of Selected Fruit Juice Concentrates Used as Osmotic Agents on the Drying Kinetics and Chemical Properties of Vacuum-Microwave Drying of Pumpkin
}

\author{
Krzysztof Lech $\mathbb{D}^{1},{ }^{1}$ Adam Figiel, ${ }^{1}$ Anna Michalska, ${ }^{2}$ Aneta Wojdyło, ${ }^{2}$ and Paulina Nowicka ${ }^{2}$ \\ ${ }^{1}$ Institute of Agricultural Engineering, Wrocław University of Environmental and Life Sciences, Wrocław, Poland \\ ${ }^{2}$ Department of Fruit, Vegetable and Plant Nutraceutical Technology, Wrocław University of Environmental and Life Sciences, \\ Wrocław, Poland
}

Correspondence should be addressed to Krzysztof Lech; krzysztof.lech@upwr.edu.pl

Received 30 November 2017; Accepted 11 February 2018; Published 18 March 2018

Academic Editor: Encarna Aguayo

Copyright @ 2018 Krzysztof Lech et al. This is an open access article distributed under the Creative Commons Attribution License, which permits unrestricted use, distribution, and reproduction in any medium, provided the original work is properly cited.

\begin{abstract}
The study examined the osmotic dehydration of pumpkin slices in chokeberry, flowering quince, and raspberry concentrated juices. Products obtained were subjected to vacuum-microwave finish drying (VMD). The objective of the study was to evaluate the drying kinetics and the chemical properties, that is, total polyphenolics content and antioxidant capacity of the vacuum-microwave-dried pumpkin products. The concentration and temperature of the juices were $40^{\circ} \mathrm{Brix}$ and $45^{\circ} \mathrm{C}$, respectively. The pumpkin slices were pretreated in concentrated juices for $0.5,1,2,3$, and 6 hours. Vacuum-microwave finish drying was carried out at the power of magnetrons that ensured the maintenance of the safe temperature (below $90^{\circ} \mathrm{C}$ ) of the slices measured with the use of infrared camera. The results of the study showed that the moisture content of samples during the pretreatment in concentrated juices was decreasing until the equilibrium stage. The logarithmic model was used to describe the drying kinetics of pumpkin during VMD. Osmotic pretreatment resulted in a decrease in colour coordinates, improved the antioxidant activity of dried product, and prolonged the duration of VMD.
\end{abstract}

\section{Introduction}

Drying is one of the most common technological operations used for prolongation of the shelf life of vegetables [1]. Pumpkin is a source of vitamins, especially ascorbic acid, riboflavin and tocopherols, carotenoids, and tannins and also minerals like magnesium, potassium, iron, phosphorus, and selenium [2]. Nevertheless, the antioxidant capacity of pumpkin flesh is relatively low. It can be improved by soaking raw materials in concentrated juices obtained from fruits containing relatively higher amounts of biologically active components. Chokeberry fruits are known as an excellent source of polyphenolic compounds [3]. On the other hand, flowering quince and raspberry fruits can be also considered due to their attractive flavour and colour [4]. Therefore, concentrated fruit juices seem to be appropriate agents for osmotic dehydration (OD) of plant materials.
During OD, three types of mass transfer occur with different intensity [5]. The first type is water flux from the raw material to the osmotic solution. The second type is the solids transfer from the solution to the raw material, while the third type consists of natural solutes migration from the raw material to the solution. The intensities of particular types of mass transfer depend on the temperature, concentration, and the kind of the osmotic solution [6]. Usually, sucrose is used to prepare an osmotic solution for dehydration of plant materials. OD in sucrose solution was applied to many raw materials such as pepper [7], strawberries [8], apples [9], or pumpkin [10]. However, osmotically predried raw material involves finish drying in order to reduce the moisture content until the safe level and to ensure the attractive texture of the final product. Among several methods used for this purpose, vacuum-microwave drying (VMD) seems to be appropriate. During VMD, the energy of microwaves is absorbed by water 
located in the whole volume of the material being dried. This creates a large vapour pressure in the centre of the material, allowing rapid transfer of moisture to the surrounding vacuum, which protects from the structural collapse [11]. As a consequence, the rate of drying is considerably higher than in traditional methods of dehydration [12]. The puffing phenomenon that accompanies the rapid process of dehydration creates a porous texture of the food and facilitates obtaining a crispy and delicate texture [13], and in this way it reduces the product's density as well as its shrinkage.

Vacuum-microwave drying (VMD) technique has already been successfully applied to reduce the moisture content of plant materials, that is, carrots [11], cranberries [14], strawberries [15], bananas [16], apples [13], pumpkin [17], and garlic [18]. At the beginning of VMD, the intensive water evaporation from the material may exceed the capacity of a vacuum pump. This would require a reduction in the quantity of the material subjected to drying or application of a large vacuum installation. This problem can be overcome by predrying of the material using OD. As a result of predrying, the mass loads of VM equipment can be radically decreased [19]. Predrying of the material by convective method before vacuum-microwave finish drying (VMD) reduced the total cost of dehydration and improved the quality of dried tomatoes [20], strawberries [21], and beetroot cubes [22]. No scientific work has been yet reported on the drying of pumpkin by the combined method consisting of osmotic pretreatment and VMD. Furthermore, the use of concentrated fruit juices instead of sucrose as an osmotic agent may have also a healthy aspect. This method of drying could make a significant contribution to the vegetable processing industry. Therefore, the main aim of this study was to evaluate the possibility of using a combination of osmotic pretreatment in concentrated chokeberry, flowering quince, and raspberry juices and VMD for processing of pumpkin flesh. The effect of osmotic pretreatment on VMD kinetics, colour, polyphenols content, and antioxidant capacity of dried product was evaluated.

\section{Materials and Methods}

2.1. Materials. Pumpkin (Cucurbita maxima Duchesne $c v$. Hokkaido) was cultivated in a field located close to Wrocław (Poland). Pumpkin flesh ( $\left.\mathrm{Mc}=6.72 \mathrm{~kg} \cdot \mathrm{kg}^{-1} \mathrm{db}\right)$ was cut into rectangular slices with dimensions of $20 \times 10 \times 5 \mathrm{~mm}$.

2.2. Osmotic Solution. Commercial concentrated fruit juices (Rauch Polska, Płońsk, Poland, $65^{\circ}$ Brix) were used in the study to prepare osmotic solutions with concentration of $40^{\circ}$ Brix: (a) chokeberry juice, (b) flowering quince juice, and (c) raspberry juice. The concentrated juices were obtained only by water removal from the natural juices; there are no additives and no conservatives added. Physical and chemical properties of osmotic solutions are provided in Table 1. The concentration of juices was measured using Atago Digital Brix Refractometer (PAL-3, Atago Co., Ltd., Tokyo, Japan). The temperature of osmotic solution was $45^{\circ} \mathrm{C}$ [23].

2.3. Osmotic Dehydration (OD). Osmotic solutions were placed in beakers immersed in the water bath at $45^{\circ} \mathrm{C}$. The ratio of osmotic solution to pumpkin slices was maintained at $3: 1$ (180 $\mathrm{ml}: 60 \mathrm{~g}$ of fresh matter). The mass of the samples was measured after $0.5,1,2,3$, and 6 hours of OD. The samples were taken out from the solution by using a tea strainer and the surplus moisture was gently eliminated from their surfaces with a tissue paper before measuring their mass.

Determination of mass transfer during osmotic dehydration (OD) was shown as the solid gain (SG) and water loss (WL) calculated by equations presented by Nowicka et al. [24].

2.4. Vacuum-Microwave Drying (VMD). VMD was performed in SM 200 dryer (Plazmatronika, Wrocław, Poland) [25]. Drying was carried out with wattage adjustment involving a reduction of microwave power from initial $480 \mathrm{~W}$ to $120 \mathrm{~W}$ to avoid overheating of the dried material. Temperature of the samples was measured by infrared camera Flir i50 (FLIR Systems AB, Sweden).

2.5. Moisture Content. The moisture content was determined using a vacuum-dryer (SPT-200; ZEAMiL Horyzont, Kraków, Poland), where samples were kept at $70^{\circ} \mathrm{C}$ at the pressure of $100 \mathrm{~Pa}$ for $24 \mathrm{~h}$.

2.6. Drying Kinetics. The drying kinetics were determined on the basis of the mass losses of the pumpkin samples. During VMD, samples were weighed every 2 and $8 \mathrm{~min}$ for $480 \mathrm{~W}$ and $120 \mathrm{~W}$, respectively, in order to get a similar energy input between the mass measurements regardless of the microwave power level. This procedure enabled obtaining similar number of measuring points for particular samples which were dried using different microwave power levels $(480 \mathrm{~W}$ or $120 \mathrm{~W})$. The drying kinetics represent decreasing of moisture ratio $(\mathrm{MR})$ in time $(t)$ of drying. MR was determined using the following equation [25]:

$$
\mathrm{MR}=\frac{M}{M_{0}},
$$

where $M$ is the actual moisture content and $M_{0}$ is the initial moisture content.

Preliminary tests conducted in this study proved that the best fitting was obtained for the logarithmic model (see (2)); consequently, only this model was used in this study, where $A, B$, and $k$ are constants.

$$
\mathrm{MR}=A \cdot e^{(-k \cdot t)}+B
$$

2.7. Colour Measurement. Colour of dried samples was measured using Minolta Chroma Meter CR-400 (Minolta Co. Ltd., Osaka, Japan). Instrumental colour data were provided as $\operatorname{CIE~} L^{*}, a^{*}$, and $b^{*}$ coordinates, which define the colour in a three-dimensional space. The total change in the colour (dE) during the VMD was calculated according to Sledz et al. [26] between dried pumpkin and fresh pumpkin.

2.8. Total Phenolics and Antioxidant Activity. Total phenolics content was measured with application of the Folin-Ciocalteu 


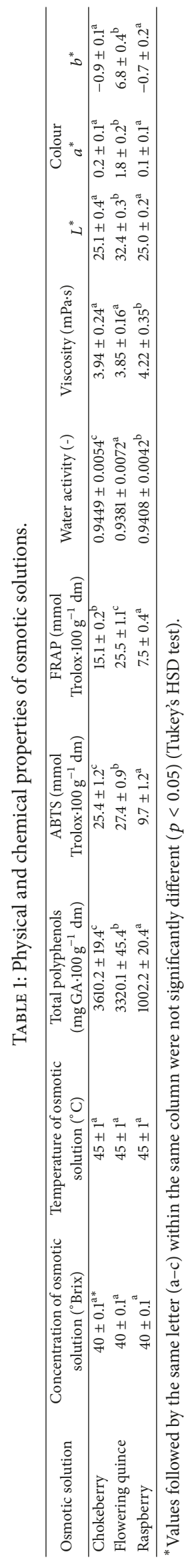


reagent with gallic acid (GA) as a standard according to Gao et al. [27]. All determinations were performed in triplicate.

The antioxidant activity of extracts was determined using the FRAP assay according to Benzie and Strain [28]. Antioxidant capacity was also determined by ABTS method, according to Re et al. [29]. Determinations by ABTS and FRAP methods were performed using a UV-2401 PC spectrophotometer (Shimadzu, Kyoto, Japan). All determinations were performed in triplicate.

2.9. Viscosity of Osmotic Solutions. Viscosity of osmotic solutions was determined using a Vibro Viscometer SV-10 (A\&D Company, Limited, Tokyo, Japan). Temperature of osmotic solution was $45^{\circ} \mathrm{C}$. The measurements were performed in triplicate.

2.10. Water Activity of Osmotic Solutions. Water activity was measured using water activity meter AquaLab Dew Point 4TE (Decagon Devices Inc., United States) at $25^{\circ} \mathrm{C} \pm 0.5$. The measurements were performed in triplicate.

2.11. Statistical Analysis. The results obtained were evaluated by statistical analysis with the use of the STATISTICA v. 12.0 (StatSoft, Inc., Tulsa, USA). Homogeneous groups were determined with Tukey's HSD test at significance level of $\alpha=0.05$. TableCurve 2D V5.01 (Systat Software, San Jose, California, USA) enabled prediction of moisture ratio (MR) by fitting the mathematical model to experimental points with the highest possible values of the determination coefficient $R^{2}$ and the lowest values of root mean square error (RMSE) [25].

\section{Results and Discussion}

3.1. Osmotic Dehydration. Figure 1 shows water loss (WL) and solid gain (SG) during dehydration of pumpkin in concentrated juices prepared from chokeberry, flowering quince, and raspberry fruits. At the beginning of the process, the mass exchange between the pumpkin and concentrates was intensive and after $1 \mathrm{~h}$, the mass exchange rate decreased. The values of water loss were almost 3 times higher than those obtained for the solid gain, regardless of the juice applied for the dehydration. A similar observation was made during osmotic dehydration of pumpkin in sucrose solution [30] and cherries in apple juice [24]. In the current study, the highest WL value was noticed during dehydration in concentrated flowering quince, whereas the lowest value was indicated during dehydration in concentrated chokeberry juice. This might result from different physical properties of osmotic solutions, that is, the value of water activity of flowering quince was $a_{w}=0.9381$, whereas $a_{w}$ of chokeberry solution was 0.9449 (Table 1). It was observed that the lower the water activity, the greater the osmotic pressure influencing the intensity of the mass exchange [6]. The value of SG was higher for flowering quince and chokeberry than for raspberry solution. This may be due to the viscosity of these solutions, which was the highest for raspberry concentrated juice (Table 1). The viscosity of the juice affects the penetration of solids from the solution to the material. An increasing viscosity of the solution results in an agglomeration of the particles. The agglomerated products might block transfer of particles into intracellular spaces [31]. After the OD process, the water content in the plant material is still relatively high; thus, to obtain more stable product, the further drying is required. Among several methods, VMD seems to be the most appropriate due to numerous advantages including shorter duration and higher efficiency of the process [32].

3.2. Vacuum-Microwave Drying (VMD). The drying kinetics of raw pumpkin and pumpkin dehydrated in concentrated fruit juices are shown in Figures 2-4. Figure 2 represents VMD kinetics of fresh pumpkin $(0 \mathrm{~h})$ and pumpkin dehydrated in concentrated chokeberry juice for $0.5,1,2,3$, and $6 \mathrm{~h}$. The duration of VMD of pumpkin was relatively short: 36 min (Table 2), whereas VMD of samples osmotically dehydrated in concentrated chokeberry juice was significantly longer, lasting up to $66 \mathrm{~min}$, depending on the time of osmotic predehydration.

Such prolongation of drying time caused by osmotic pretreatment can be explained by a decrease of water diffusivity within the dried material enriched in water-binding substances absorbed from the concentrated juice. Another factor that prevents the removal of water from the dried material was the blockage of pores by the same substances, which additionally enhanced the increase in temperature of the sample during the VMD. The temperature of VMD material depends on the internal pressure of water vapour, which is closed in the plant cellular system [22]. Probably, the impregnation of cell walls which occurs during the osmotic dehydration process leads it to be less permeable to water vapour. This may explain both the higher temperature and lower drying rates when comparing the OD samples and raw material. A similar observation was made for VMD beetroots [25] and chokeberries [33] dehydrated in chokeberry juice. Similar results were obtained during drying of pumpkins dehydrated in concentrated flowering quince (Figure 3) and raspberry juice (Figure 4). In the case of pumpkin dehydrated in flowering quince concentrated juice, the time of VMD was slightly shorter (Table 2), since the fresh material lost a higher quantity of water in this osmotic solution. From this point of view, osmotic pretreatment in concentrated juices increases the energy consumption of the entire drying process. However, osmotic dehydration in concentrate solutions prepared from fruits with beneficial bioactive compounds can significantly increase the quality of dried material $[4,34]$.

The decrease of moisture ratio (MR) during the microwave-vacuum drying process was described by a logarithmic model (see (2)). Values of parameters $A$ and $B$ as well as the drying constant $k$ are presented in Table 2. Parameter $A$ describes the MR value at the beginning of the drying process $(t=0 \mathrm{~min})$ and it is strongly correlated with the moisture content of the samples before the VMD, whereas parameter $B$ is the value of the asymptote function, which is strongly correlated with the final moisture content of the samples $\left(\mathrm{Mc}_{w b}\right)$. Drying constant $(k)$ for pretreated samples was higher $(0.183-0.240)$ than for samples dried without osmotic pretreatment $(0.128)$. This was due to the fact that the amount of water in the dehydrated samples was lower and 


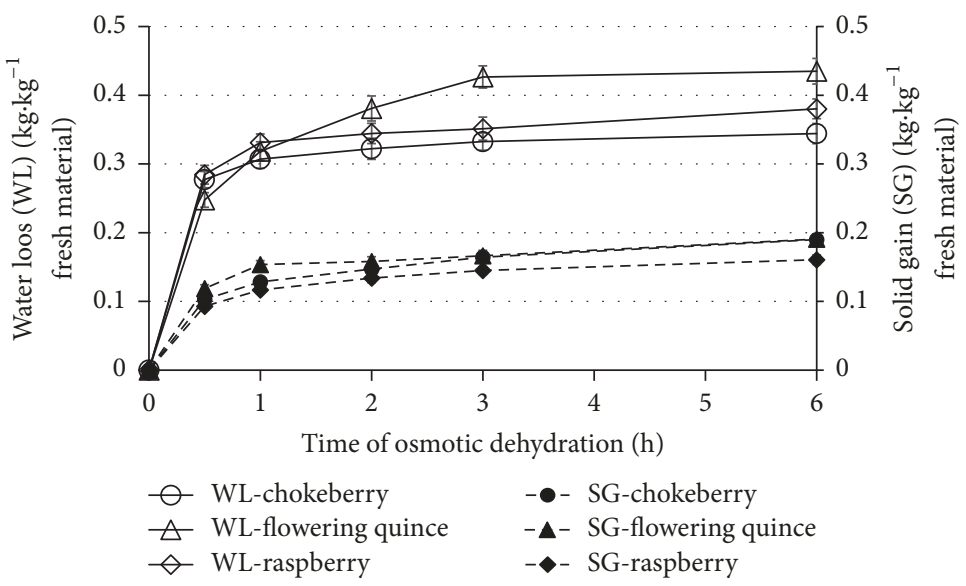

FIGURE 1: Water loss and solid gain during osmotic dehydration of pumpkin in three concentrated juices: chokeberry, flowering quince, and raspberry.

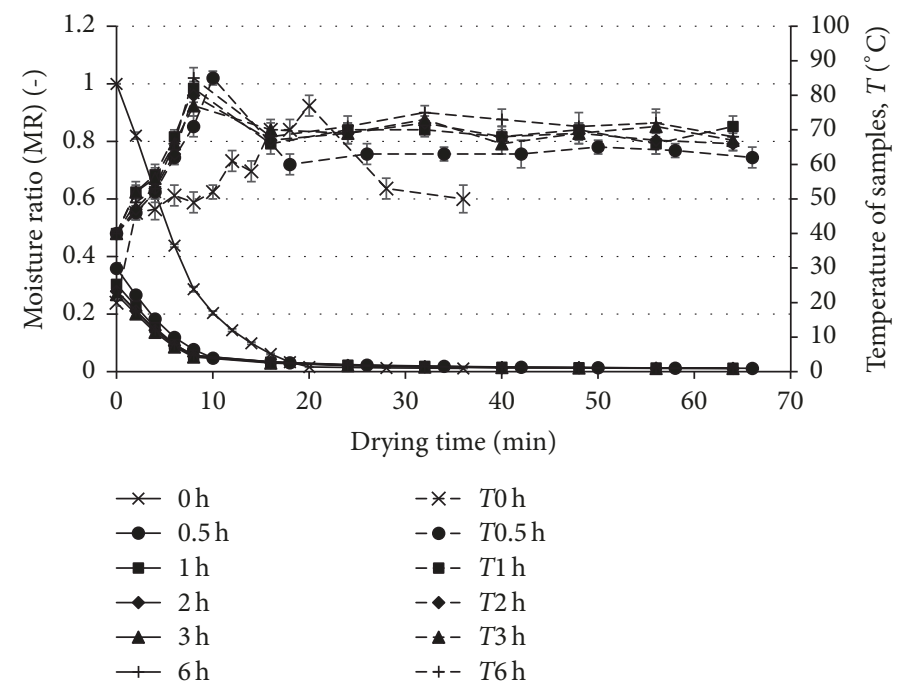

FIGURE 2: Vacuum-microwave finish drying of pumpkin after osmotic dehydration in chokeberry juice.

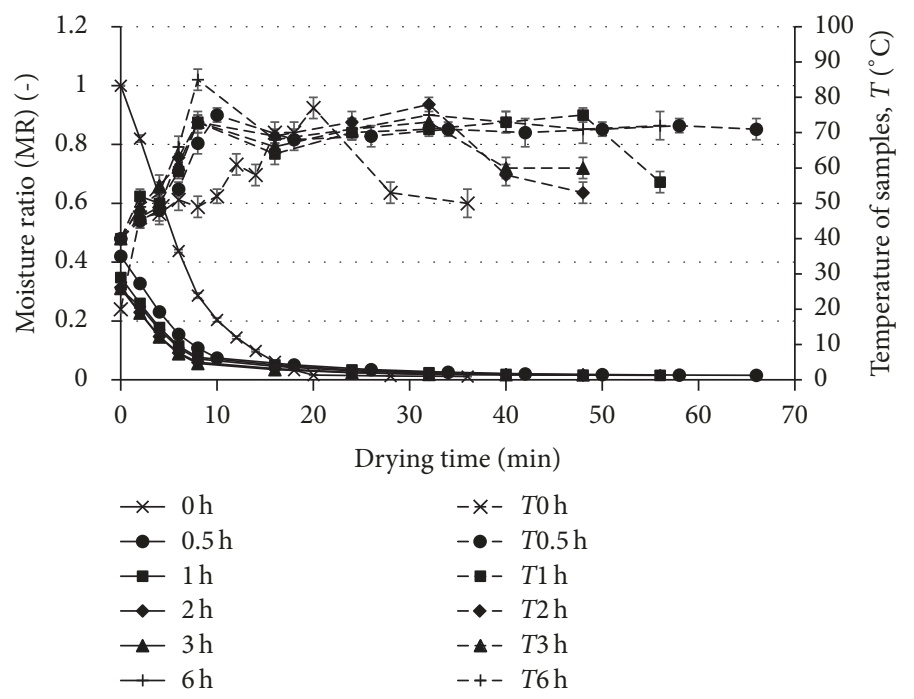

FIGURE 3: Vacuum-microwave finish drying of pumpkin after osmotic dehydration in flowering quince juice. 


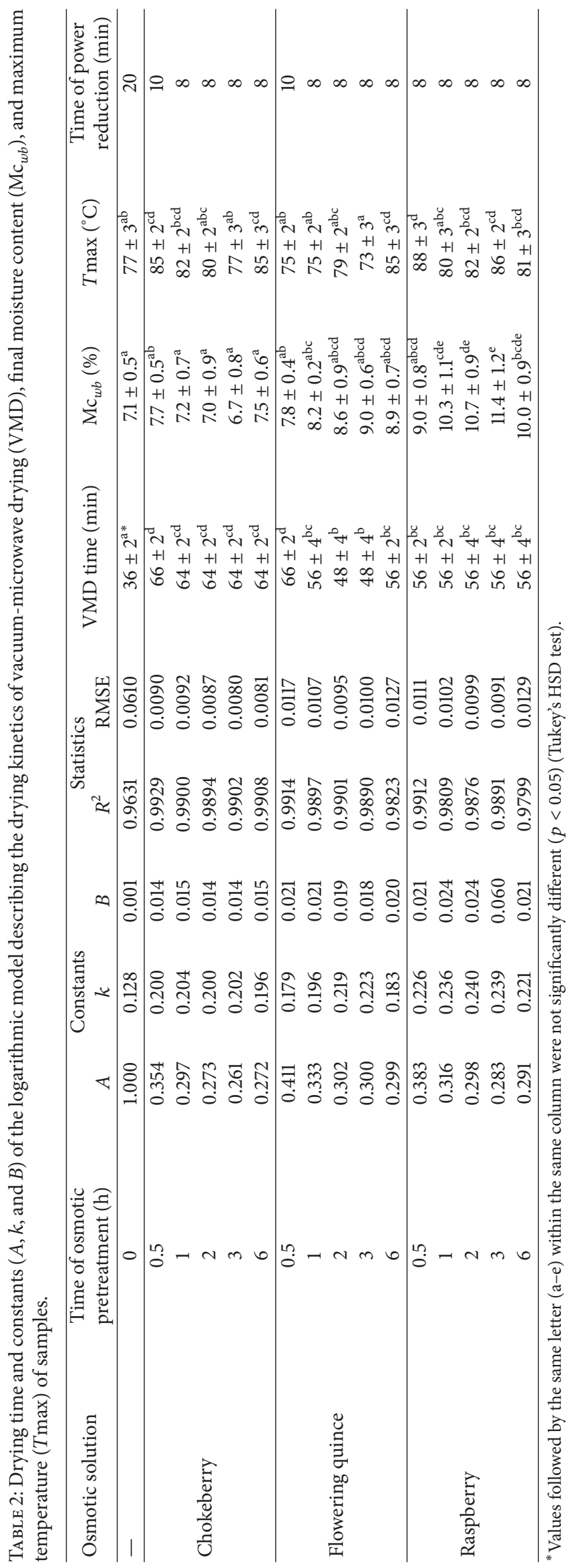




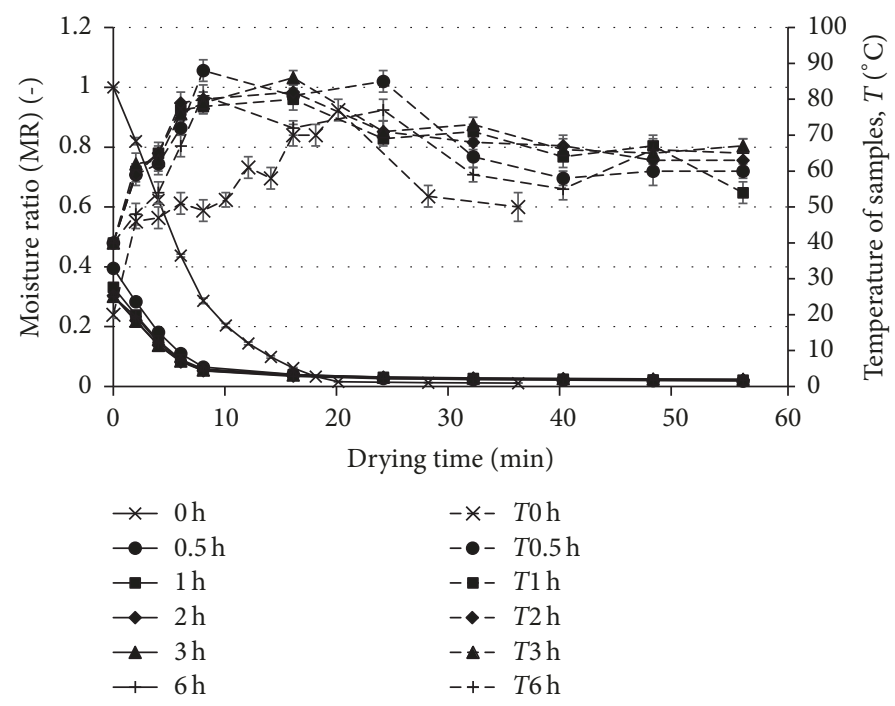

FIGURE 4: Vacuum-microwave finish drying of pumpkin after osmotic dehydration in raspberry juice.

the time necessary for drying the raw material was longer. Values of determination coefficient $R^{2}$ for all tested samples were in the range from 0.9631 to 0.9914 (Table 1), while the values of root mean square error (RMSE) were below 0.129 , indicating good fitting of mathematical functions to empirical points. Similar values of $R^{2}$ were obtained while describing a pumpkin drying process using a logarithmic model [35]. The final moisture content of the sample was between $6.7 \%$ and $11.4 \%$, which guarantees stable products [36]. The maximum temperature of the samples obtained during the VMD depended on the duration of application of magnetron power of $480 \mathrm{~W}$. It was assumed that when the temperature was around $80^{\circ} \mathrm{C}$, the power would be reduced to $120 \mathrm{~W}$. Table 2 shows the time of VMD when the power was reduced due to the temperature increase. The power reduction caused a significant reduction in the samples temperature (Figures 2-4). A similar relationship was obtained during VMD of cherries [37] and chokeberries [33].

3.3. Polyphenolics Content and Antioxidant Activity. The content of polyphenols (PC) and antioxidant capacity of fresh and dried samples are shown in Table 3. Similar values of PC and ABTS antioxidant activity for fresh pumpkin of Hokkaido variety were obtained by Obradović et al. [38]. For nonosmotically dehydrated pumpkin subjected to VMD process, a decrease in PC was observed after drying and the values of antioxidant capacity were reduced. During drying of biological materials, degradation of polyphenolic compounds occurs, which results in decreasing of antioxidant activity. This relationship was observed during drying of cherries [16], different cultivars of pumpkin [39], and blueberries [40]. The application of OD prior to VMD resulted in an increase in the content of polyphenol compounds, which significantly increased the antioxidant capacity of the dried product. OD performed by only 0.5 hours in the concentrated chokeberry juice caused a more than 5-fold increase in the content of polyphenolic compounds. A further OD process increased the content of these compounds, which after $6 \mathrm{~h}$ was more than 10 times greater than that in the fresh pumpkin. The increase in polyphenolic compounds was related to the penetration of solids from the osmotic solution to the dehydrated material. Similar results were observed during the dehydration of beetroots [25] and cherries [4] in concentrated chokeberry juice. Even greater increase in PC was obtained for pumpkin dehydrated in concentrated flowering quince juice. In the case of pumpkin samples dehydrated in raspberry juice, the increase was only over 2 times. Similar results were obtained for cherries dehydrated in concentrated flowering quince and raspberry juices [4]. It can be concluded that the dehydration in osmotic solutions improves the quality of the final products in terms of the content of biologically active components [41].

3.4. Colour Parameters. The colour parameters of fresh and dried samples were shown in Table 4. Colour measurement of fresh and dried pumpkin concerned the surface of the samples. The values of colour coordinates $L^{*}=64.41, a^{*}=$ 22.81 , and $b^{*}=55.14$ determined for fresh pumpkin were used as a base for determination of $\Delta E^{*}$. VMD resulted in a reduction of all colour parameters, which is typical for this method of drying [17]. Osmotic dehydration resulted in the change of dried pumpkin colour $\left(\Delta E^{*}\right)$, which ranged from 27.6 to 76.3 compared to the colour of fresh pumpkin. Such a large colour change was related to the colour of the fruit concentrates used for OD (Table 1). The substance from the osmotic solution, penetrating into the dehydrated material, changed the colour of the material [42]. The longer the dehydration time is, the more the colour parameters of the samples shift toward the colour parameters of the juice. The osmotic dehydration process in concentrated fruit juices can enhance the appearance of the dried fruit by concealing the unattractive natural discolouration of fruits and vegetables 


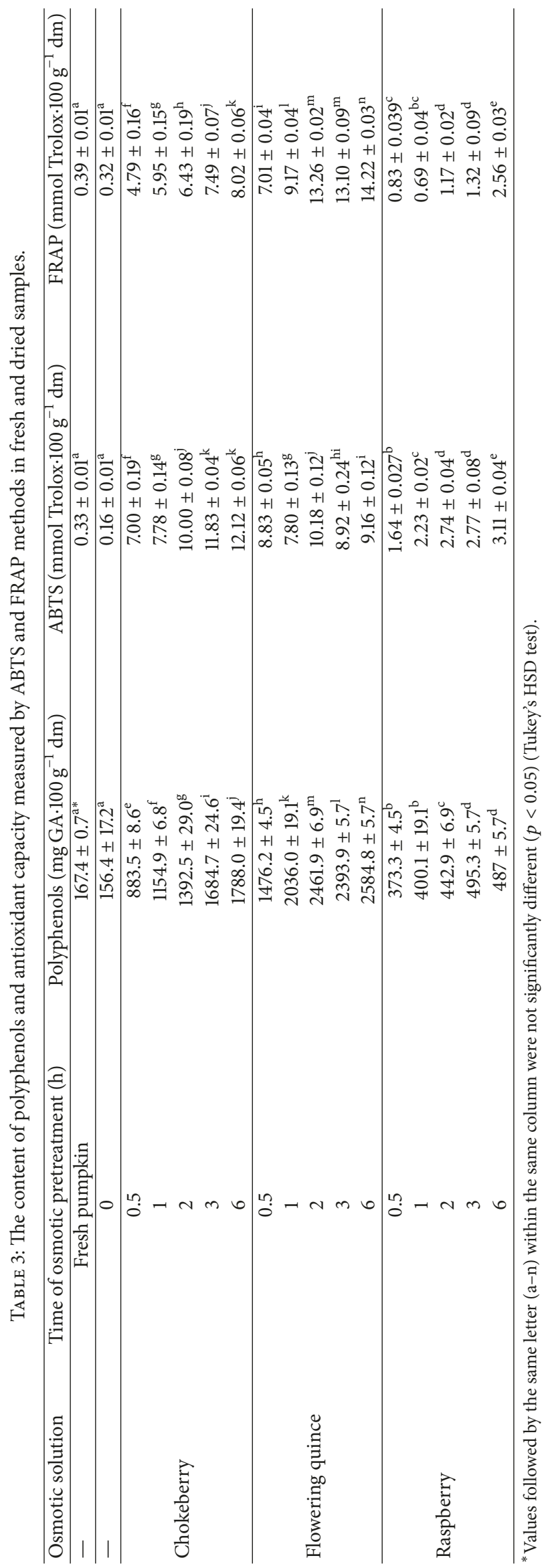




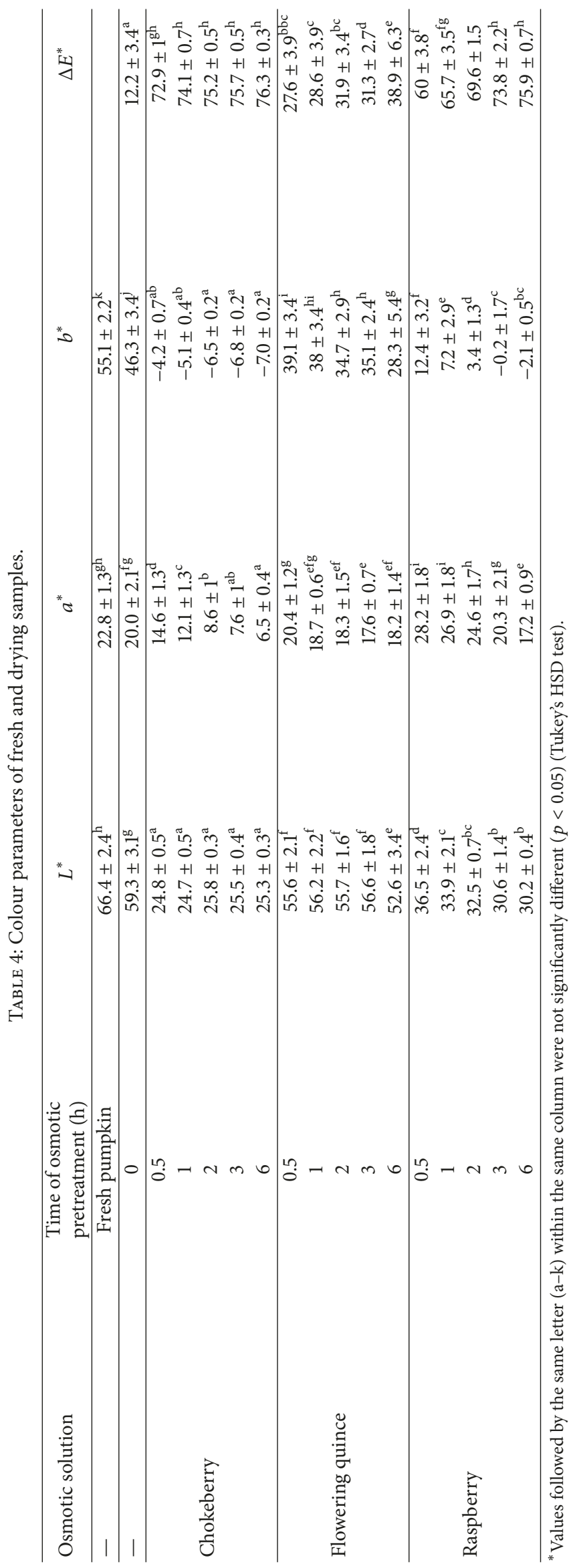


or colour alteration arises during harvesting, transport, and storage.

\section{Conclusions}

On the basis of the results obtained, it was concluded that the decrease in moisture ratio of the pumpkin slices during microwave-vacuum drying process could be described by a logarithmic model. The process of OD prolonged the time of microwave-vacuum finish drying and increased the temperature of samples during VMD due to the impregnation of wall cells by the substances absorbed from the concentrated juices. The absorption of these substances also decreased the values of colour parameters $L^{*}, a^{*}$, and $b^{*}$ and significantly increased the bioactivity of VMD pumpkin samples in terms of polyphenols content and antioxidant activity. The highest content of polyphenolic compounds and the stronger antioxidant capacity were noted when the flowering quince concentrated juice was used for the osmotic dehydration process due to the highest values of solid gain.

\section{Conflicts of Interest}

The authors declare that there are no conflicts of interest regarding the publication of this paper.

\section{Acknowledgments}

This work was funded by the science budget for the years 2010-2013 as Research Project no. N N312 338039 and by the National Science Centre (Poland) based on the Decision no. UMO-2014/15/D/NZ9/0524.

\section{References}

[1] A. Figiel and A. Michalska, "Overall quality of fruits and vegetables products affected by the drying processes with the assistance of vacuum-microwaves," International Journal of Molecular Sciences, vol. 18, no. 1, article no. 71, 2017.

[2] Y. Terazawa, K. Ito, R. Masuda, and K. Yoshida, "Changes in Carbohydrate Composition in Pumpkins(Kabocha) during Fruit Growth," Journal of the Japanese Society for Horticultural Science, vol. 70, no. 5, pp. 656-658, 2001.

[3] J. Oszmiański and A. Wojdylo, "Aronia melanocarpa phenolics and their antioxidant activity," European Food Research and Technology, vol. 221, no. 6, pp. 809-813, 2005.

[4] P. Nowicka, A. Wojdyło, K. Lech, and A. Figiel, "Chemical Composition, Antioxidant Capacity, and Sensory Quality of Dried Sour Cherry Fruits pre-Dehydrated in Fruit Concentrates," Food and Bioprocess Technology, vol. 8, no. 10, pp. 20762095, 2015.

[5] A. L. Raoult-Wack, "Recent advances in the osmotic dehydration of foods," Trends in Food Science \& Technology, vol. 5, no. 8, pp. 255-260, 1994.

[6] A. Lenart and P. Lewicki, "Osmotic dehydration of fruits and vegetables," in Handbook of Industrial Drying, CRC Press, 3rd edition, 2006, ISBN 978-1-57444-668-5.

[7] K. O. Falade and O. O. Oyedele, "Effect of osmotic pretreatment on air drying characteristics and colour of pepper (Capsicum spp) cultivars," Journal of Food Science and Technology, vol. 47, no. 5, pp. 488-495, 2010.

[8] D. Piotrowski, A. Lenart, and A. Wardzyński, "Influence of osmotic dehydration on microwave-convective drying of frozen strawberries," Journal of Food Engineering, vol. 65, no. 4, pp. 519525, 2004.

[9] K. O. Falade, T. O. Akinwale, and O. O. Adedokun, "Effect of drying methods on osmotically dehydrated cashew apples," European Food Research and Technology, vol. 216, no. 6, pp. 500504, 2003.

[10] M. Shafafi Zenoozian and S. Devahastin, "Application of wavelet transform coupled with artificial neural network for predicting physicochemical properties of osmotically dehydrated pumpkin," Journal of Food Engineering, vol. 90, no. 2, pp. 219-227, 2009.

[11] T. M. Lin, T. D. Durance, and C. H. Scaman, "Characterization of vacuum microwave, air and freeze dried carrot slices," Food Research International, vol. 31, no. 2, pp. 111-117, 1998.

[12] G. P. Sharma and S. Prasad, "Effective moisture diffusivity of garlic cloves undergoing microwave-convective drying," Journal of Food Engineering, vol. 65, no. 4, pp. 609-617, 2004.

[13] P. W. Y. Sham, C. H. Scaman, and T. D. Durance, "Texture of vacuum microwave dehydrated apple chips as affected by calcium pretreatment, vacuum level, and apple variety," Journal of Food Science, vol. 66, no. 9, pp. 1341-1347, 2001.

[14] P. S. Sunjka, T. J. Rennie, C. Beaudry, and G. S. V. Raghavan, "Microwave-convective and microwave-vacuum drying of cranberries: A comparative study," Drying Technology, vol. 22, no. 5, pp. 1217-1231, 2004.

[15] A. Wojdyło, A. Figiel, and J. Oszmiański, "Effect of drying methods with the application of vacuum microwaves on the bioactive compounds, color, and antioxidant activity of strawberry fruits," Journal of Agricultural and Food Chemistry, vol. 57, no. 4, pp. 1337-1343, 2009.

[16] N. Mousa and M. Farid, "Microwave vacuum drying of banana slices," Drying Technology, vol. 20, no. 10, pp. 2055-2066, 2002.

[17] A. Nawirska, A. Figiel, A. Z. Kucharska, A. Sokół-Łetowska, and A. Biesiada, "Drying kinetics and quality parameters of pumpkin slices dehydrated using different methods," Journal of Food Engineering, vol. 94, no. 1, pp. 14-20, 2009.

[18] A. Figiel, "Drying kinetics and quality of vacuum-microwave dehydrated garlic cloves and slices," Journal of Food Engineering, vol. 94, no. 1, pp. 98-104, 2009.

[19] Q.-G. Hu, M. Zhang, A. S. Mujumdar, G.-N. Xiao, and S. Jincai, "Drying of edamames by hot air and vacuum microwave combination," Journal of Food Engineering, vol. 77, no. 4, pp. 977-982, 2006.

[20] T. D. Durance and J. H. Wang, "Energy consumption, density, and rehydration rate of vacuum microwave- and hot-air convection- dehydrated tomatoes," Journal of Food Science, vol. 67, no. 6, pp. 2212-2216, 2002.

[21] V. Böhm, S. Kühnert, H. Rohm, and G. Scholze, "Improving the nutritional quality of microwave-vacuum dried strawberries: A preliminary study," Food Science and Technology International, vol. 12, no. 1, pp. 67-75, 2006.

[22] A. Figiel, "Drying kinetics and quality of beetroots dehydrated by combination of convective and vacuum-microwave methods," Journal of Food Engineering, vol. 98, no. 4, pp. 461-470, 2010.

[23] M. Cano-Lamadrid, K. Lech, A. Michalska et al., "Influence of osmotic dehydration pre-treatment and combined drying 
method on physico-chemical and sensory properties of pomegranate arils, cultivar Mollar de Elche," Food Chemistry, vol. 232, pp. 306-315, 2017.

[24] P. Nowicka, A. Wojdyło, K. Lech, and A. Figiel, "Influence of Osmodehydration Pretreatment and Combined Drying Method on the Bioactive Potential of Sour Cherry Fruits," Food and Bioprocess Technology, vol. 8, no. 4, pp. 824-836, 2015.

[25] K. Lech, A. Figiel, A. Wojdyło, M. Korzeniowska, M. Serowik, and M. Szarycz, "Drying Kinetics and Bioactivity of Beetroot Slices Pretreated in Concentrated Chokeberry Juice and Dried with Vacuum Microwaves," Drying Technology, vol. 33, no. 13, pp. 1644-1653, 2015.

[26] M. Śledź, M. Nowacka, A. Wiktor, and D. Witrowa-Rajchert, "Selected chemical and physico-chemical properties of microwave-convective dried herbs," Food and Bioproducts Processing, vol. 91, no. 4, pp. 421-428, 2013.

[27] X. Gao, M. Ohlander, N. Jeppsson, L. Björk, and V. Trajkovski, "Changes in antioxidant effects and their relationship to phytonutrients in fruits of sea buckthorn (Hippophae rhamnoides L.) during maturation," Journal of Agricultural and Food Chemistry, vol. 48, no. 5, pp. 1485-1490, 2000.

[28] I. F. F. Benzie and J. J. Strain, "The ferric reducing ability of plasma (FRAP) as a measure of 'antioxidant power': the FRAP assay," Analytical Biochemistry, vol. 239, no. 1, pp. 70-76, 1996.

[29] R. Re, N. Pellegrini, A. Proteggente, A. Pannala, M. Yang, and C. Rice-Evans, "Antioxidant activity applying an improved ABTS radical cation decolorization assay," Free Radical Biology \& Medicine, vol. 26, no. 9-10, pp. 1231-1237, 1999.

[30] C. C. Garcia, M. A. Mauro, and M. Kimura, "Kinetics of osmotic dehydration and air-drying of pumpkins (Cucurbita moschata)," Journal of Food Engineering, vol. 82, pp. 284-291, 2007.

[31] S. Antonyuk, S. Heinrich, N. Deen, and H. Kuipers, "Influence of liquid layers on energy absorption during particle impact," Particuology, vol. 7, no. 4, pp. 245-259, 2009.

[32] Á. Calín-Sánchez, A. Figiel, F. Hernández, P. Melgarejo, K. Lech, and Á. A. Carbonell-Barrachina, "Chemical Composition, Antioxidant Capacity, and Sensory Quality of Pomegranate (Punica granatum L.) Arils and Rind as Affected by Drying Method," Food and Bioprocess Technology, vol. 6, no. 7, pp. 16441654, 2013.

[33] Á. Calín-Sánchez, A. Kharaghani, K. Lech, A. Figiel, Á. A. Carbonell-Barrachina, and E. Tsotsas, "Drying Kinetics and Microstructural and SensoryProperties of Black Chokeberry (Aronia melanocarpa) as Affected by Drying Method," Food and Bioprocess Technology, vol. 8, no. 1, pp. 63-74, 2014.

[34] I. Escriche, R. Garcia-Pinchi, A. Andrés, and P. Fito, "Osmotic dehydration of kiwifruit (Actinidia chinensis): Fluxes and mass transfer kinetics," Journal of Food Process Engineering, vol. 23, no. 3, pp. 191-205, 2000.

[35] R. P. F. Guiné, S. Pinho, and M. J. Barroca, "Study of the convective drying of pumpkin (Cucurbita maxima)," Food and Bioproducts Processing, vol. 89, no. 4, pp. 422-428, 2011.

[36] A. Ciurzyńska, A. Lenart, and K. J. Greda, "Effect of pre-treatment conditions on content and activity of water and colour of freeze-dried pumpkin," LWT- Food Science and Technology, vol. 59, no. 2, pp. 1075-1081, 2014.

[37] A. Wojdyło, A. Figiel, K. Lech, P. Nowicka, and J. Oszmiański, "Effect of convective and vacuum-microwave drying on the bioactive compounds, color, and antioxidant capacity of sour cherries," Food and Bioprocess Technology, vol. 7, pp. 829-841, 2014.
[38] V. Obradović, J. Babić, D. Šubarić, A. Jozinović, D. Ačkar, and I. Klarić, "Influence of dried Hokkaido pumpkin and ascorbic acid addition on chemical properties and colour of corn extrudates," Food Chemistry, vol. 183, pp. 136-143, 2015.

[39] A. Nawirska-Olszańska, B. Stępień, and A. Biesiada, "Effectiveness of the fountain-microwave drying method in some selected pumpkin cultivars," LWT- Food Science and Technology, vol. 77, pp. 276-281, 2017.

[40] M. Zielinska and A. Michalska, "Microwave-assisted drying of blueberry (Vaccinium corymbosum L.) fruits: Drying kinetics, polyphenols, anthocyanins, antioxidant capacity, colour and texture," Food Chemistry, vol. 212, pp. 671-680, 2016.

[41] A. Rózek, I. Achaerandio, C. Güell, F. López, and M. Ferrando, "Grape phenolic impregnation by osmotic treatment: Influence of osmotic agent on mass transfer and product characteristics," Journal of Food Engineering, vol. 94, no. 1, pp. 59-68, 2009.

[42] A. S. Abraão, A. M. Lemos, A. Vilela, J. M. Sousa, and F. M. Nunes, "Influence of osmotic dehydration process parameters on the quality of candied pumpkins," Food and Bioproducts Processing, vol. 91, no. 4, pp. 481-494, 2013. 


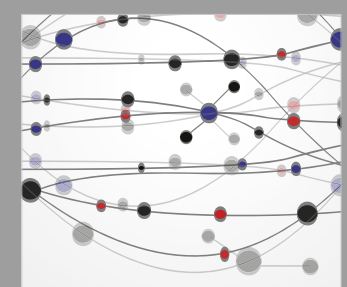

The Scientific World Journal
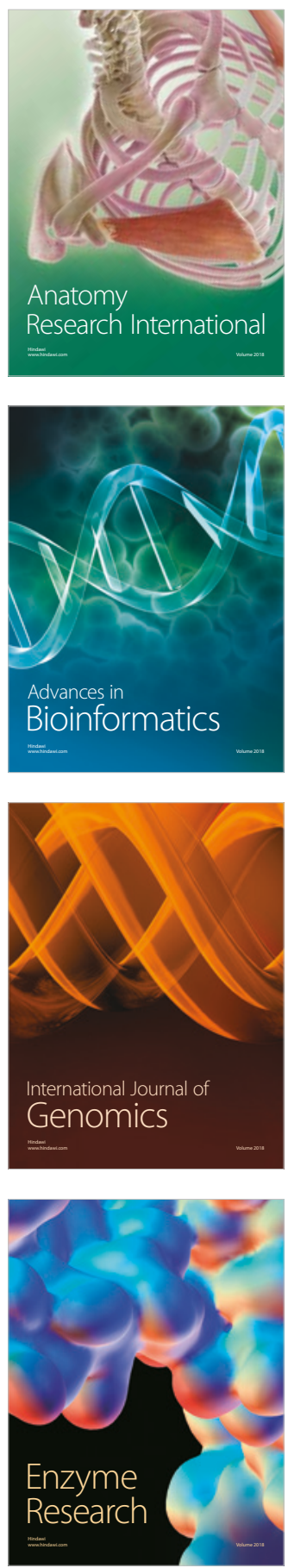
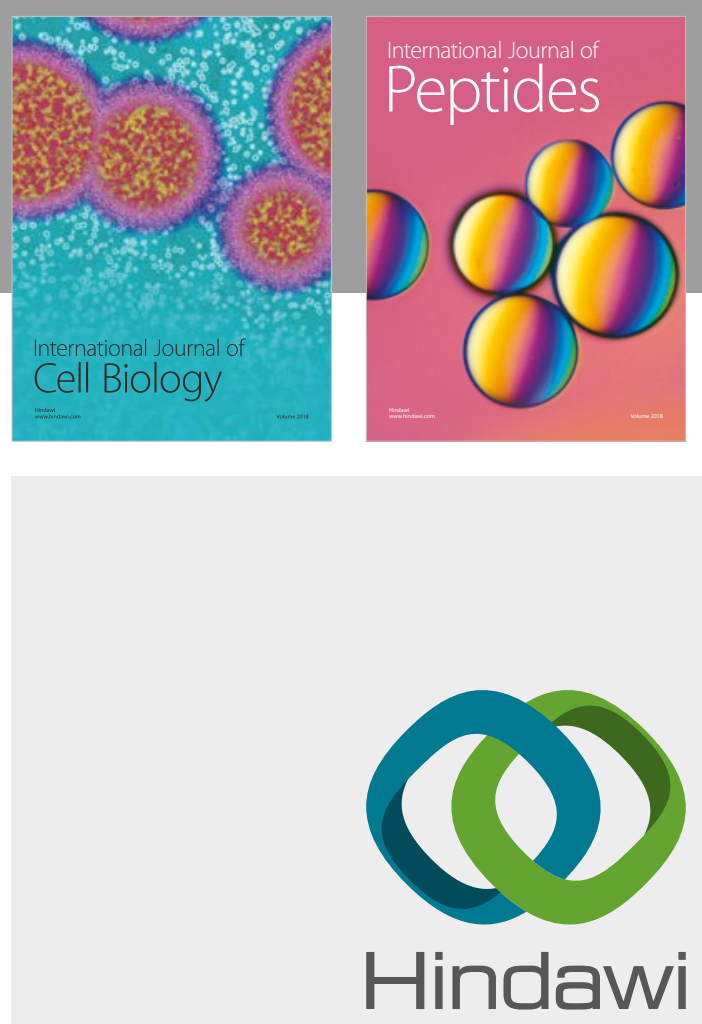

Submit your manuscripts at

www.hindawi.com
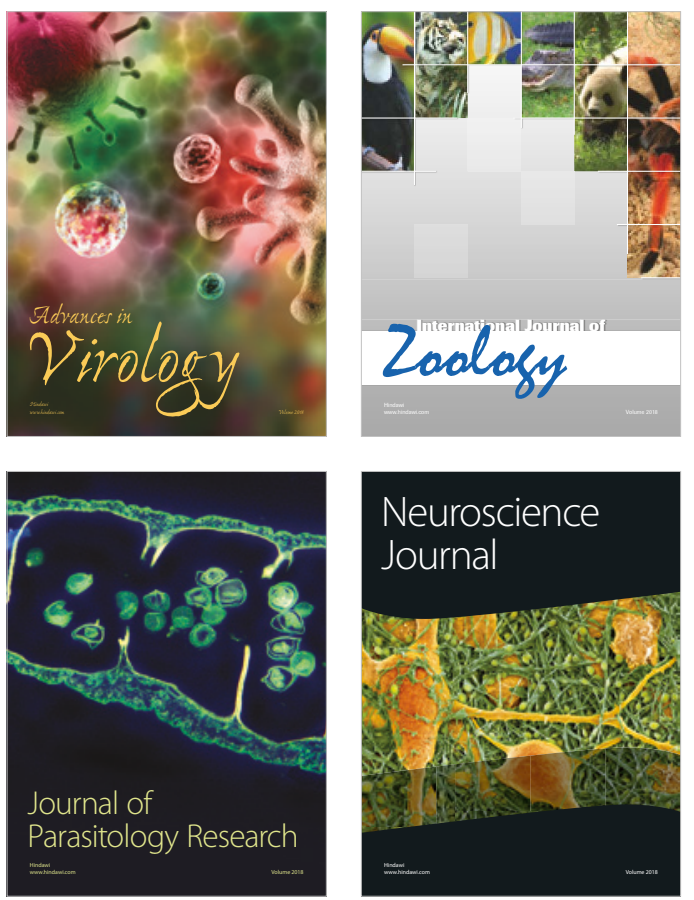
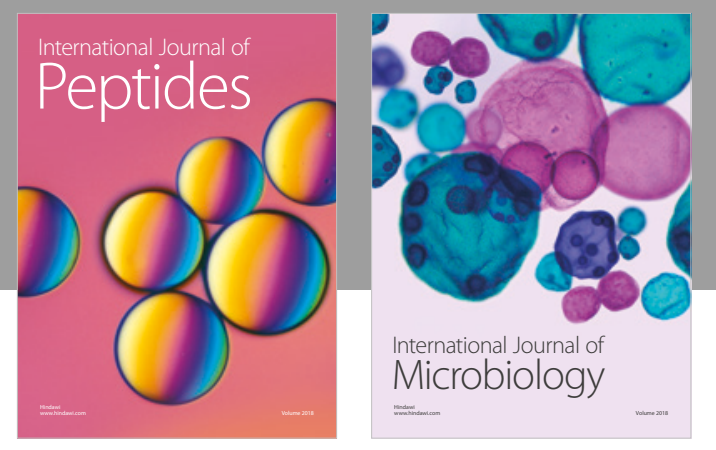

nternational Journal of Microbiology
Journal of
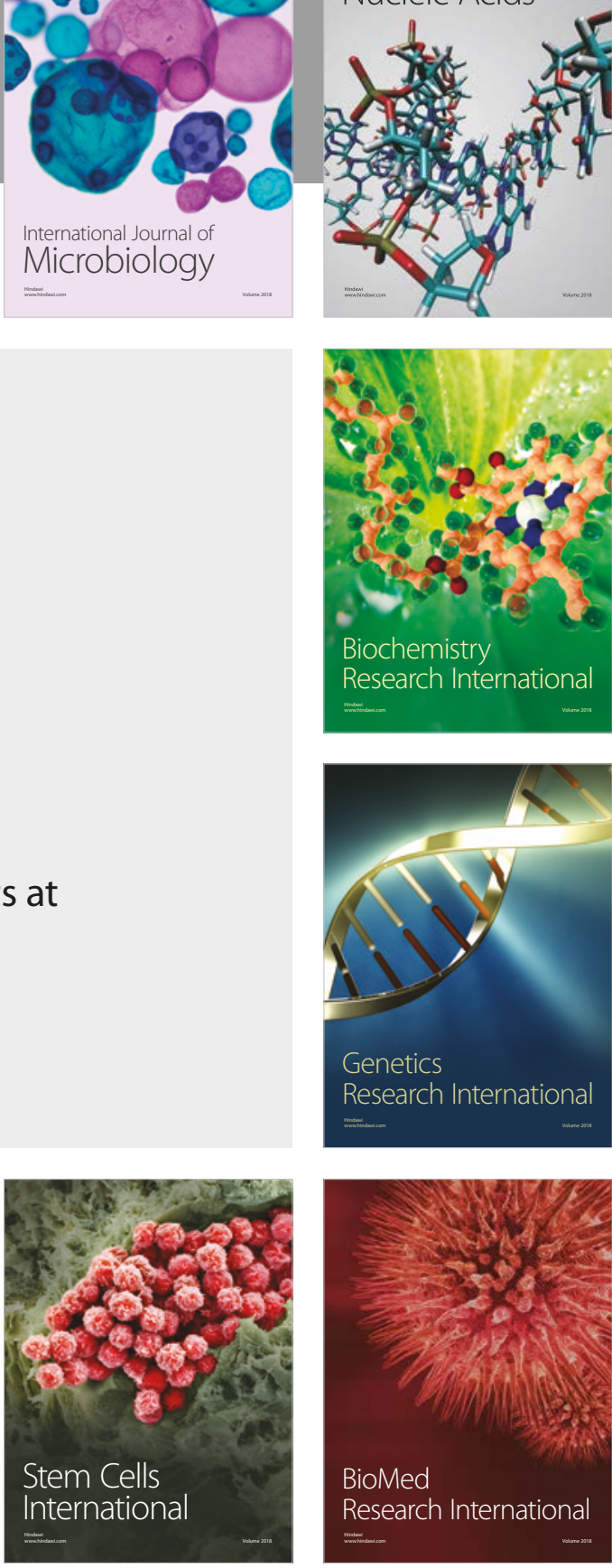
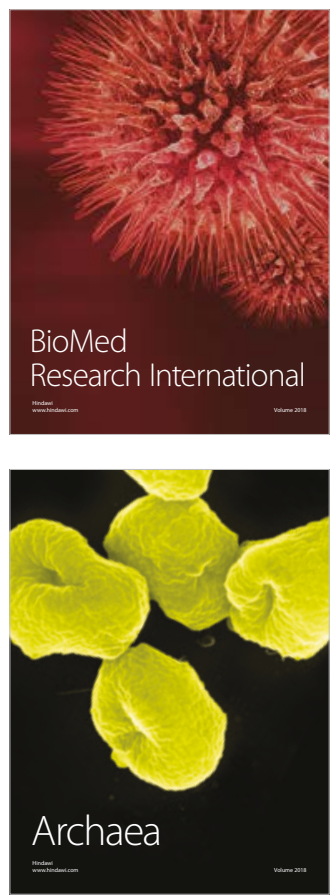